DOI: https://doi.org/10.47405/aswj.v5i1.114

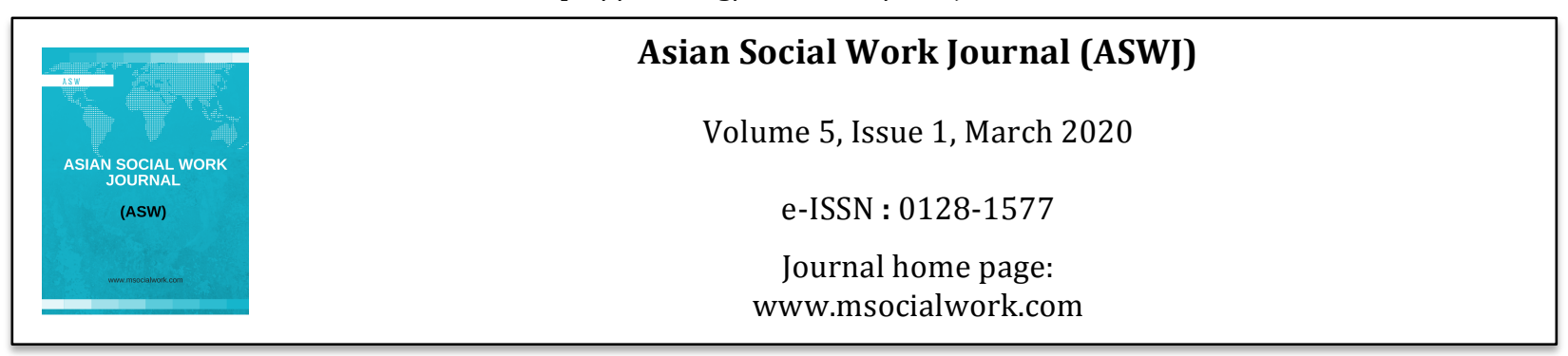

\title{
Social Work Services for Children With Autism and Their Families in Vietnam
}

\author{
Nguyen Trung Hai ${ }^{1}$ \\ 1 University of Labor and Social Affairs, Vietnam \\ Correspondence: Nguyen Trung Hai (haiguyentrung1979@gmail.com)
}

\begin{abstract}
In Vietnam, autism has only been known for more than 10 years, but it has quickly become a burden not only for family with autistic children, but also a burden for the whole society. Although there is no official published data, the number of children diagnosed and treated with autism at public health facilities has increased from 2000 to the present, higher than the previous year. The models of care, intervention, support for autistic children and their families in the world are taking a holistic approach and emphasizing the role of social work services because these services cover from internal Prevention, Intervention, Recovery and Development for children with autism and their families. For Vietnam, social work for a young job is only officially recognized as a job through the project No: 32/2010/QDTTg "Development of social work careers in the period of 2010 - 2020". In current conditions in Vietnam, social work services in the community are still new and in the process of development. Research results show that facilities are making efforts in providing social work services to autistic children and their families. However, because of many different reasons, these services have not really developed in a professional way. This limits the effectiveness of interventions with autistic children and their families in the current context in Vietnam.
\end{abstract}

Key words: social work, social work services, autism, service providers, facilities

\section{Introduction}

In Vietnam, recent data show that the number of children diagnosed and treated with autism at public health facilities has been increasing, the following year is higher than the previous year (Dau Tuan Nam \& Vu Hai Van, 2015). In the current context, many children with autism for a very long time, but were not detected and used social services by parents and relatives to intervene. This situation is caused by a lack of understanding or inaccurate knowledge of parents about autism. Therefore, they also lack knowledge about services in general and social work services in particular in supporting and interfering with this syndrome of their children. Along with that is the awareness of the community and society in the work of caring, protecting and ensuring the rights of children facing many limitations, leading to many autistic children not being detected and intervened in time being unable to integrate into the surrounding social environment, having to depend on the care of family members, discrimination in the community. For Vietnam, social work is quite a new job when officially recognized as a profession through the project No: 32/2010/QD-TTg "Development of social work careers in the period of 20102020 ". In current conditions in Vietnam, social work services in the community are still new and in the process of development. Therefore, it is necessary to conduct researches that formulate specific strategies and solutions in developing social work services for disadvantaged groups in general and for children and families with autism in particular. The study was conducted in 2019 in 3 areas: Hanoi city, 


\section{Asian Social Work Journal (ASWJ), Volume 5, Issue 1, (page 12 - 17), 2020 DOI: https://doi.org/10.47405/aswj.v5i1.114}

Ho Chi Minh city and Quang Ninh city with 10 social work service providers (5 Non-Government facilities and 5 Government facilities).

\section{Findings about social work services for autistic children and their families}

The implementation of this research is based on a comprehensive service delivery approach for autistic children and their families. The holistic approach to service delivery is based on the assumption that clients have many different problems, and they are all related to each other. Therefore, if the problem is solved alone, it will not be completely solved. So the issues need to be addressed radically through the provision of diverse and comprehensive services. The comprehensive service delivery approach is implemented in accordance with Clause 1 Article 47 of the Children's Law in 2016 in Vietnam. Specifically, the services should be provided in intervention and support for autistic children and their families, including Preventive services; Intervention services and; Support Recovery/Development Services. In the field of social work services for autistic children and their families, based on a comprehensive service delivery approach, specific social work services are categorized separately for children with autism and for their families. For families having autistic children, the services are divided into 2 groups: Preventive services group and Intensive Intervention services group. For autistic children, the services are divided into 3 groups which are the Initial intervention service group, the Intensive intervention service group and the Integration/Development support service group.

Documents review shows that most of the social work services have not been implemented much in non-government facilities or health facilities, educational institutions. These institutions often focus on interventions and therapies for autistic children, such as teaching children about language and communicating with gestures and pictures, regulating sensory movement, and teaching skills. independent activities, interactive play and group activities about sports, games, physical exercises, music ... Only a few facilities have community integration services or psychotherapy for young parents. However, it can be seen that these services have not been implemented professionally.

For government facilities providing social work services such as social work centers, social protection centers... because they have social work departments or devision, so that social work services for autistic children and family are more concentrated. Based on Project 32/2010, these facilities and centers have participated in many basic training courses on social work ingenenral as well as social work in interventions to support autistic children and their families. Thus the staff capacity has been improved and social work services are gradually being formed and provided professionally in these facilities. Based on semi-structured questionnaire for Government and Non-Government facility leaders as well as through surveys of social work services providers for autistic children and their families, statistic is analyzed specifically below.

\section{Social work services for Families with Autistic children}

For families with autistic children, the types of social work services mainly focus on Preventive services and Intensive intervention services. Preventive services include: Advocacy; Propaganda for raising awareness of families, schools and communities ... and Intensive intervention services including: Mobilizing and Connecting resources; Advocacy; Case management, Psychological counseling; Policy advice; Educating knowledge about autism.

Table 1: Social work services for families with autistic children

\begin{tabular}{|c|c|c|c|}
\hline $\begin{array}{l}\text { Social work services } \\
\text { Preventive services }\end{array}$ & $\begin{array}{c}\text { Frequent } \\
\text { implementing }\end{array}$ & $\begin{array}{c}\text { Less } \\
\text { implementing }\end{array}$ & $\begin{array}{c}\text { No } \\
\text { implementing }\end{array}$ \\
\hline - Propaganda to families & $8 / 10$ & $1 / 10$ & $1 / 10$ \\
\hline - Propaganda to community & $5 / 10$ & $4 / 10$ & $1 / 10$ \\
\hline - Propaganda to school & $3 / 10$ & $5 / 10$ & $2 / 10$ \\
\hline
\end{tabular}


DOI: https://doi.org/10.47405/aswj.v5i1.114

\begin{tabular}{llcc}
\hline$\quad$ Intensive intervention services & & & \\
- Mobilizing and Connecting resources & $3 / 10$ & $5 / 10$ & $2 / 10$ \\
- Case management & $2 / 10$ & $4 / 10$ & $4 / 10$ \\
- Advocacy & $2 / 10$ & $1 / 10$ & $7 / 10$ \\
- Psychological counseling & $6 / 10$ & $2 / 10$ & $2 / 10$ \\
- Policy advice & $5 / 10$ & $4 / 10$ & $1 / 10$ \\
- Educating knowledge about autism & $8 / 10$ & $2 / 10$ & 0 \\
\hline
\end{tabular}

Source: Results from this research, 2019

Looking at the results in Table 1, it can be seen that preventive services are more deployed by service providers than intensive intervention services. Specifically, propaganda services to families are regularly implemented by most establishments ( $8 / 10$ facilities). Propaganda services to the community and the family are also carried out to varying degrees. In fact, at present, both Government and NonGovernment establishments providing autistic services to children and their families are mostly paidservices. Therefore the provision of services in a certain aspect will be operated according to the market mechanism. This means that in order for the service to be used more, facilities must promote the advertising and communication of the service to beneficiaries. When people know about the facility's service, the quality and strengths of the service are well known, it is an important factor to attract people to use the service. Therefore, facilities are quite interested in propaganda and communication services as the research results shown above. However, it should be noted that the communication services here are not merely advertising about the service, the service provider, but also aiming to provide knowledge and raise awareness about autism. People understand and prevent possible risk factors for autism as well as communication to reduce stigma and discrimination against this group. That is essentially a preventive service.

For intensive services with families, the study focused on evaluating a number of services such as: Mobilizing and Connecting resources; Advocacy; Case management, Psychological counseling; Policy advice; Educating knowledge about autism... The results show that this service is not provided as often as a preventive service. The most frequent service is the education that provides autistic knowledge to the child's family. It can be seen that the facilities themselves understand very well the importance of coordination between Family - School and - Care facilities, so beside the Propaganda services to School and enhancing the quality of services in Care facilities, they always create favorable conditions and encourage families to improve Family knowledge for better caring and supporting children. The next services are policy consultations and psychological consultations for parents of autistic children.

The policy advisory and stress relief consultations are also regularly conducted by the facilities. Clearly stemming from the above factual analysis, the biggest problem that the parents currently face which is the psychological stress. Moreover, as mentioned above, in order for parents to participate in child care, in addition to providing knowledge, counseling and psychological sharing are very important. Therefore facilities are always interested and focused to this issue.

Activities such as Mobilization of resources, Referral, and Advocacy in intensive family intervention services are not regularly conducted by many facilities, especially non-Government facilities. A closer look at this issue shows that there are two main causes. Firstly, due to the nature of the type of nongovvernment facilities, income-generating activities and services are focused. Moreover, work force in this type of facilities are often limited in number and mostly interventions or administrative work. Therefore, they do not have enough staff and expertise to carry out these services. Here only some facilities that regularly carry out this services are Government facilities. Stemming from the nature of the facility that both intervenes and provides services, it is supported by the State in terms of funding as well as functions and people to carry out good advocacy, mobilizing resources so they still implement this services. However, as described above, in terms of quantity and coverage, non-government facilities are dominating. Therefore, if these facilities do not pay much attention or are not provided with favorable conditions to carry out these services, then low income families will face many difficulties and less opportunities to access and use those services. 
DOI: https://doi.org/10.47405/aswj.v5i1.114

\section{Social work services for Children with Autism}

For autistic children's services, the research focuses on researching and analyzing 3 main types of services: the Initial intervention service group, the Intensive intervention service group and the Integration/Development support service group. Initial intervention services include activities such as: Preliminary assessment; Screening; Diagnosis... Intensive intervention services are direct treatment interventions to help children with autism recover the limitations of communication and social interaction; and Integration and development services such as: Support for intergrated and special education, conslting and vocational training support, setting up support networks in the community... The implementation of these services is described in detail in the table 2 below here.

Table 2: Social work services for children with autism

\begin{tabular}{|c|c|c|c|}
\hline $\begin{array}{c}\text { Social work services } \\
\text { Initial intervention service } \\
\end{array}$ & $\begin{array}{c}\text { Frequent } \\
\text { implementing }\end{array}$ & $\begin{array}{c}\text { Less } \\
\text { implementing }\end{array}$ & $\begin{array}{c}\text { No } \\
\text { implementing }\end{array}$ \\
\hline - Preliminary assessment & $8 / 10$ & $1 / 10$ & $1 / 10$ \\
\hline - Screening & $7 / 10$ & $2 / 10$ & $1 / 10$ \\
\hline - Diagnosis & $6 / 10$ & $4 / 10$ & 0 \\
\hline Intensive intervention service & & & \\
\hline - $\quad$ RDI (Relationship Development Intervention) & $7 / 10$ & $1 / 10$ & $2 / 10$ \\
\hline - ABA (Applied behavior analysis) & $2 / 10$ & $4 / 10$ & $4 / 10$ \\
\hline $\begin{array}{l}\text { - TEACCH (The Treatment and Education of } \\
\text { Autistic and Communication related handicapped } \\
\text { Children) }\end{array}$ & $3 / 10$ & $3 / 10$ & $4 / 10$ \\
\hline $\begin{array}{l}\text { - PECS (Picture Exchange Communication System) } \\
\text { Integration/Development support service }\end{array}$ & $5 / 10$ & $2 / 10$ & $3 / 10$ \\
\hline - Integrated and Special education & $6 / 10$ & $2 / 10$ & $2 / 10$ \\
\hline - Consulting and Vocational training & 0 & $2 / 10$ & $8 / 10$ \\
\hline - Establish a support network in the community & 0 & $3 / 10$ & $7 / 10$ \\
\hline
\end{tabular}

Source: Results from this research, 2019

Table 2 shows that the activities in the initial intervention service for children with autism are routinely conducted by autism service providers. The most frequently implemented services is the Preliminary Assessment and Screening when enrolling autistic children in grassroots interventions. Preliminary assessments will help the staff collect basic information not only about the child but also the child's family context. A screening is then needed to determine if the child's problem is autism. Ultimately, the diagnosis will help determine the child's autism as well as the level of autism the child is experiencing in order to develop an appropriate treatment intervention plan. Not only at the facility, but even for families it is essential to receive these activities in the beginning when accessing services. This was agreed by families during the research interview. The only facility that does not perform these two activities is the Social Work Center in Hanoi because the center currently only provides basic services for different target groups. The initial intervention services such as assessment or screening require dmuch knowledge about autism. However the staff here is not qualified so that they do not implement that services.

Intensive intervention services for children with autism are treatment and interventions in the area of special education or psychology. In fact, there is no such content in current formal training programs on social work. Therefore, in theory, this is not considered as a social work service. However, in practical contexts, due to human resources difficulties in facilities, so being a social worker, they still carry out these services. The staff here will be sent to short-term training courses on autism so that these interventions can be implemented. Therefore, within this study, intensive intervention services are considered part of the social work service to create a comprehensive service group in support and care for children with autism. Analysis more detail in this service, it can be seen that facilities do not have specific standards for interventions, so each facility has its own intervention. However, most of the therapeutic interventions for autistic children focus on two main interventions: RDI (Relationship Development Intervention) and PECS (Picture Exchange Communication System). These 2 interventions are quite simple and suitable for both children and staff. As known, autistic children have 
limitations on social interaction, so implementing RDI will help them develop good social relationships. And pictorial intervention is an effective intervention because children have the ability to express their thoughts and desires. Gradually, the child will be directed to express his/her desired needs better. However, in fact, providing intervention services should base on type of autism and the level of autism. It is, definitely, the most effective intervention for autistic children. So facilities also have to develop more intensive intervention to have various treatment for each autistic child.

In addition, it is very important to emphasize that the intensive interventions services for autistic children must be recognized by the scientific community through scientific journals. Staff conducting these interventions must also have a professional qualification and have undergone socially accepted formal training, updating themselves with continuous knowledge to behave and take care autistic children effectively. However, it can be said that the incident at the center for autistic children training became the record that the press published recently, about the type of education that went against the values and philosophy in interventions with autistic children. The content of intensive interventions for autistic children is not entirely based on scientific evidence for improvement of functional behavior but only on the expression of 1-2 cases from the facility's advertising. Their actions have seriously harmed autistic children both physically, mentally and humanly. With service providers currently lacking standards in terms of intervention tools, it is difficult to control these contents. Therefore, no one dared to accept responsibility for the effectiveness of the intervention. Therefore, it is necessary to have the involvement of the authorities in the promulgation of the standard set of interventions, along with specific criteria to evaluate the effectiveness of interventions with autistic children. Just the effectiveness of such interventions will be guaranteed.

Integration/Development support service do not seem to be implemented by facilities, both government and non-government, especially vocational training and community support networks services are not implemented regularly. Discussing about this issue, government facilities believe that they have just established and implemented autism care services so they should focus on developing interventions first. Moreover, the contingent of officials is not much, not enough capacity to implement. Similarly, non-government facilities also focus heavily on therapeutic activities. As part of the facility's leadership, most of them have medical expertise, so they think the mission of this service provider is to treat autism interventions. Integrated development services are the responsible of community social workers.

In fact, there are many interventions to care for autistic children. There are comprehensive care models both Physical - Psychological - Social in 1 facility. However, there are also specialized therapeutic care facilities in one area, while others carry out referrals and connections to other facilities or the community to implement services which beyond the functionality and capabilities of their facility. For all of approaches mentioned above, social workers are very needed to be those facilites to carry out case management, establish relationships and connect with the community and other services to meet the needs of autistic children and their family. This is the model that government and non-government facilites can use when their resources are not enough to follow the comprehensive service model.

\section{Conclussion}

The results of the study show that service delivery with a comprehenshive approach has been implemented. However, in most of the service providers, most of them cannot guarantee the full provision of comprehensive services.

Parents of autistic children lack knowledge about autism. This leads to ineffective child care at home as well as ineffective of coordination between the family and care facilities in caring for autistic children.

Autistic parents also lack information on social work services. Therefore, the access and use of these services is also limited. 
DOI: https://doi.org/10.47405/aswj.v5i1.114

Some service providers do not yet have a full awareness of social work services. This is one of the reasons why these services have not been fully implemented.

Policies to support autistic children and families are still limited. This has led to difficulties for social service providers due to the lack of resources to support autistic children and their families.

Non-government facilities focus on intensive interventions with autistic children, and other social work services have not been implemented. This reason comes from the fact that the leadership of these institutions is almost exclusively specialized in health or special education so the field of social work is not known or paid attention. Moreover, due to the fact that they are non-non facilties, they have to pay much attention to the economic issue, so the staff of these facilities also focus on those who provide intensive intervention services. Other social work services are not much of their concern.

For government facilities, because their mandate to provide social work services, they have focused on the implementation of services in the field of social work. However, due to difficulties in recruiting new service providers, some institutions have to take advantage of staff with specialties other than social work and send them to attend short-term training courses to enhance their qualification in this area. Therefore, in terms of capacity, officials are still limited because they have not yet been able to ensure in-depth expertise in providing social work services to autistic children and their families.

\section{References}

Center for Research and Education and Child Care (2011). Supporting knowledge about the care and education of children with autism spectrum disorder. Vietnam National University of Education Publishing House

Dau Tuan Nam, Vu Hai Van (2015). Policy for autistic children in Vietnam. Social and Sience journal in Vietnam. No 11(96) - 2015

Decree 103 (2017). Regulations on the establishment, organization, operation, dissolution and management of social assistance institutions.

Doan Huu Minh \& Nguyen Trung Hai (2019). Development of social work services in Vietnam. SSRG International Journal of Humanities and Social Science (SSRG-IJHSS) - Volume 6 Issue 3 May - June 2019.

Law on child care and protection (2004)

Law on Marriage and Family (2000).

Le Khanh (2017). Handbook for child psychology.

National Conference on Autism in America (1999). Autism and issues that need attention

Nguyen Trung Hai \& Dang Quang Trung (2018). Situation of using social service of child with mental health problem in Vietnam. Internaitonal workshop.

Nguyen Hai Huu (2017). Social work services with children. International workshop. 